\title{
Perdas causadas pela ferrugem-asiática em cultivares de soja semeadas em diferentes épocas, no Oeste da Bahia
}

\author{
Thyane V. da Cruz ${ }^{1}$, Clovis P. Peixoto ${ }^{1}$, Mônica C. Martins², Francisco F. Laranjeira ${ }^{3}$, Pedro V. Lima \\ Lopes $^{4}$, Newton S. Andrade ${ }^{5} \&$ Carlos A. da Silva Ledo ${ }^{3}$
}

${ }^{1}$ Universidade Federal do Recôncavo da Bahia, 44380-000, Cruz das Almas, BA, Brasil; ${ }^{2}$ Faculdade Arnaldo Horácio Ferreira, 47850-000, Luís Eduardo Magalhães, BA, Brasil; ${ }^{3}$ EMBRAPA Mandioca e Fruticultura, 44380-000, Cruz das Almas, BA, Brasil; ${ }^{4}$ Galvani Indústria, Comércio e Serviços, 47850-000, Luís Eduardo Magalhães, BA, Brasil; ${ }^{5}$ Agência Estadual de Defesa Agropecuária da Bahia (ADAB), 47807-080, Barreiras, BA, Brasil

Autor para correspondência: Thyane Viana da Cruz, e-mail: thyvc@yahoo.com.br

\begin{abstract}
RESUMO
Este trabalho teve como objetivo quantificar os danos causados pela ferrugem-asiática em três cultivares de soja, semeadas em diferentes épocas, na região Oeste da Bahia. Os experimentos foram instalados no município de São Desidério, BA, nas safras 2007/2008 e 2008/2009. O delineamento experimental foi em blocos casualizados com quatro repetições, no esquema de parcelas subdivididas no espaço. A parcela foi representada pelos tratamentos de controle da ferrugem (com ou sem aplicação de fungicida) e as subparcelas foram representadas pelas cultivares (Monsoy 8411, BRS Corisco e BRS Barreiras). Avaliou-se a severidade da ferrugem para o cálculo da área abaixo da curva de progresso da doença padronizada (AACPDp), o número de folhas ao longo do ciclo e a produtividade de grãos. O modelo logístico foi o que melhor se ajustou aos dados da severidade. A variação temporal do número de folhas foi ajustada pela função polinomial exponencial $\mathrm{Ln}(\mathrm{y})=\mathrm{a}+\mathrm{bx}^{1,5}+\mathrm{cx}^{0,5}$. As médias da AACPDp e a da produtividade foram comparadas pelo teste de Tukey a $5 \%$ de probabilidade. Os danos causados pela ferrugem-asiática da soja na região foram potencializados na época de semeadura tardia, ocorrendo desfolha antecipada e redução na produtividade de grãos.
\end{abstract}

Palavras-chave: Glycine max, Phakopsora pachyrhizi, produtividade.

\begin{abstract}
Yield loss caused by rust in soybean cultivars sown in different periods in the western region of Bahia, Brazil

The objective of this work was to quantify the yield loss caused by Asian soybean rust in three cultivars sown in different periods in the western region of Bahia. The experiments were installed in São Desidério, BA, in the growing seasons 2007/2008 and 2008/2009. The experimental design was carried out in random blocks with four replicates and subdivided plot scheme in time. The plot was represented by the rust control treatments (with and without chemical control) and the subplots represented by cultivars (Monsoy 8411, BRS Corisco and BRS Barreiras). The severity, number of leaves throughout the cycle and yield were evaluated. The logistic model was the one that better fitted the severity data whereas the polynominal exponential function $\operatorname{Ln}(\mathrm{y})=\mathrm{a}+\mathrm{bx}^{1,5}+\mathrm{cx}^{0,5}$ fitted the temporal variation of number of leaves better. The means of the area under the disease progress curve and yield were compared by Tukey test. Yield loss increased during later sowing periods due to greater inoculum pressure hindering disease control and decreasing grain yield.
\end{abstract}

Key words: Glycine max, Phakopsora pachyrhizi, yield.

\section{INTRODUÇÃO}

A ferrugem-asiática da soja (FAS), causada pelo fungo Phakopsora pachyrhizi Syd. \& P. Syd., é uma das doenças mais destrutivas de soja (Sinclair \& Hartman, 1999). O primeiro relato dessa doença foi no Japão, em 1903 (Hennings, 1903), de onde o patógeno se disseminou para a África (Ono et al., 1992; Rytter et al. 1984) e para a América do Sul (Yorinori et al., 2005). A soja é suscetível a $P$. pachyrhizi em qualquer estádio de desenvolvimento (Melching et al., 1989) e as perdas decorrentes do seu ataque variam de 13 a $80 \%$ do rendimento da cultura (Ogle et al., 1979; Yang et al., 1990; Yang, 1991; Sinclair \& Hartman, 1995).
No Brasil, a FAS tem causado perdas significativas na produtividade desde a safra $2000 / 2001$, contribuindo para o incremento dos custos de produção. Na safra de 2003/2004, atingiu praticamente todas as áreas de plantio do país, exceto os Estados de Roraima e do Amapá, com perdas estimadas em 4,6 milhões de toneladas, correspondendo a US\$ 1,22 bilhão de dólares (Yorinori et al., 2004).

No Oeste da Bahia, a ferrugem foi constatada na safra 2002/2003, causando perdas estimadas em $400.000 \mathrm{t}$ (CONAB, 2003). Na safra 2008/2009, a doença foi mais severa na Bahia em função da ocorrência de chuvas melhor distribuídas e do uso de cultivares mais tardias (Consórcio Antiferrugem, 2009). 
A aplicação de fungicidas ainda é o principal método de controle da FAS na maioria das regiões produtoras. Segundo Hikishima et al. (2010), em condições climáticas favoráveis, um número elevado de pulverizações é exigido para o controle da doença, aumentando os custos de produção. Na safra 2008/2009, em média, foram realizadas 4,2 pulverizações de fungicidas no Oeste da Bahia, valor considerado alto para o manejo da doença que prevê em média duas pulverizações (Martins, 2009).

A quantificação de danos é um ponto chave na definição de qualquer estratégia de controle de doenças. A obtenção de estimativas confiáveis dos prejuízos causados pelos patógenos é considerada pré-requisito essencial para o desenvolvimento de programas bem sucedidos de controle. Nesse sentido, a utilização de modelos matemáticos e a análise de curvas de progresso da doença tem importância crescente, uma vez que permitem o monitoramento de doenças por meio de avaliações da severidade no tempo (Bergamin Filho, 1995).

As doenças podem ser quantificadas por métodos diretos de avaliação dos sintomas e sinais, como a incidência e severidade, e métodos indiretos, como a determinação da população do patógeno, sua distribuição espacial, a desfolha causada e seus efeitos na produção.

Considerando a importância da cultura da soja para região Oeste da Bahia, onde ocupa $59 \%$ da matriz produtiva (AIBA, 2011) e congrega mais de mil produtores, justificase o interesse na busca de informações sobre o manejo da cultura que possa reduzir custos de produção e aumentar produtividade, observando as peculiaridades do sistema produtivo regional.

A sojicultura baiana envolve produtores que chegam a cultivar até 40 mil hectares. As épocas de semeadura indicadas para a região Oeste da Bahia variam de meados de novembro ao final dezembro, havendo curto intervalo de semeadura (dois meses), frente à extensão territorial das propriedades (Cruz et al., 2010). Assim, muitos produtores são levados a escalonar a semeadura para otimização do maquinário e a semeadura total das áreas, praticando semeaduras em épocas mais tardias.

Considerando que a semeadura no início da época recomendada é indicada como uma medida de manejo da ferrugem-asiática (Furlan, 2005), torna-se importante a quantificação de danos nas diferentes épocas de semeadura. Para tanto, objetivou-se quantificá-los em três épocas de semeadura, em três cultivares de diferentes ciclos de maturação, na região Oeste da Bahia.

\section{MATERIAL E MÉTODOS}

Os experimentos foram instalados nas safras 2007/2008 e 2008/2009 no campo experimental da Fundação Bahia, na Fazenda Maria Gabriela, município de São Desidério, BA, situado a $728 \mathrm{~m}$ de altitude, na latitude de $12^{\circ} 45^{\prime} 30^{\prime}$ 'S e longitude $45^{\circ} 57^{\prime} 16^{\prime \prime} \mathrm{W}$. O clima é classificado como Aw da classificação de Köppen, com temperaturas médias anuais de $24^{\circ} \mathrm{C}$, e precipitação média anual de $1.200 \mathrm{~mm}$, distribuídos entre os meses de novembro e março. O período seco é bem definido entre abril e setembro, demarcando duas estações climáticas distintas: a chuvosa e a seca (AIBA, 2011). O solo é de classe textural francoargilo-arenoso, textura média. As correções e as adubações para instalação dos experimentos foram realizadas de acordo com a análise química do solo e baseadas na recomendação para a cultura da soja (EMBRAPA, 2007).

Na safra 2007/2008, as semeaduras foram realizadas em 29/11/2007 (EP1 ou primeira época de semeadura), 20/12/2007 (EP2 ou segunda época de semeadura) e 12/01/2008 (EP3 ou terceira época de semeadura). Na safra 2008/2009 as semeaduras foram realizadas em 04/12/2008 (EP1), 22/12/2008 (EP2) e 14/01/2009 (EP3). As EP1 e EP2 representam o início e o final do período preferencial de semeadura na região e as EP3, representam as épocas tardias. As cultivares utilizadas foram Monsoy 8411 (ciclo de maturação precoce), BRS Corisco (ciclo médio) e BRS Barreiras (ciclo tardio), escolhidas por serem as mais plantados e/ou de maior interesse para a região.

Para cada época de semeadura foi instalado um experimento no delineamento em blocos casualizados, com quatro repetições, no esquema de parcelas subdivididas no espaço. A parcela foi representada pelos tratamentos de controle da ferrugem (com ou sem aplicação de fungicida) e as subparcelas foram representadas pelos três cultivares (Monsoy 8411, BRS Corisco e BRS Barreiras).

A subparcela foi constituída por oito linhas de $5,0 \mathrm{~m}$ de comprimento, com espaçamento de $0,5 \mathrm{~m}$ nas entrelinhas e 10 plantas $\mathrm{m}^{-1}$. Duas linhas foram utilizadas para contagem das folhas por plantas (amostra destrutiva) e três para a determinação da produtividade de grãos. As duas linhas externas e uma das centrais foram consideradas como bordaduras, assim como $0,5 \mathrm{~m}$ de cada extremidade das demais linhas.

As aplicações de fungicidas foram realizadas a partir da constatação dos primeiros sintomas, com reaplicações a cada 15 dias até o estádio R6 ou R7.1, com pulverizadores tratorizados, utilizando pyraclostrobina + epoxiconazole $\left(66,5+25\right.$ g i.a. ha $\left.{ }^{-1}\right)$ que equivale a dose de $500 \mathrm{~mL} \mathrm{ha}^{-1} \mathrm{do}$ produto comercial e volume de calda de $200 \mathrm{~L} \mathrm{ha}^{-1}$.

Foram avaliados a severidade da ferrugem e das doenças de final de ciclo, o número de folhas por planta e a produtividade de grãos. Para essas determinações foi realizado o acompanhamento fenológico da cultura, de acordo com os estádios de desenvolvimento da soja (Fehr \& Caviness, 1981).

Para as avaliações de severidade, a cada semana foram coletadas folhas, na área útil de cada parcela, até o início do amarelecimento das folhas e vagens (R6/R7). Nos estádios iniciais de desenvolvimento da cultura, o número de folíolos coletados variou de acordo com o número total de folhas na planta. Do florescimento até o final das avaliações foram coletados 10 folíolos do terço inferior, 10 do terço médio e 10 do terço superior das plantas, perfazendo um 
total de 30 folíolos por parcela. Estimou-se a severidade com base na escala diagramática para a ferrugem-asiática da soja (Godoy et al.,2006).

Para a determinação do número de folhas por planta foram realizadas coletas aleatórias quinzenais de cinco plantas aleatórias nas linhas destinadas às amostras destrutivas em cada parcela, a partir dos trinta dias após a emergência (DAE) estendendo-se até a senescência das folhas, sendo este parâmetro obtido pela contagem direta do número de folhas.

Para determinação da produtividade de grãos, no estádio R9, as plantas da área útil de cada parcela foram colhidas com roçadora costal e trilhadas em máquina estacionária. Os grãos foram pesados em balança com capacidade de $5 \mathrm{~kg}$, determinando-se sua umidade, posteriormente corrigida para o valor de $13 \%$.

Os dados foram submetidos à análise da variância para cada ano de ensaio. O modelo logístico por regressão não-linear foi ajustado aos valores de severidade média da doença ao longo do tempo. A área abaixo da curva de progresso da doença (AACPD) foi estimada com as avaliações de severidade e a área abaixo da curva de progresso da doença padronizada (AACPDp) foi calculada dividindo-se o valor da AACPD pelo número total de dias da epidemia (Campbel \& Madden, 1990; Madden et al., 2007). As médias da AACPDp e da produtividade foram comparadas pelo teste de Tukey $(\mathrm{P}<0,05)$. A função polinomial exponencial $\operatorname{Ln}(\mathrm{y})=\mathrm{a}+\mathrm{bx}^{1,5}+\mathrm{cx}^{0,5}$, onde $(\mathrm{y})$ é a variável número de folhas, em função do tempo, sendo a, b e c os coeficientes empíricos determinados estatisticamente e $\mathrm{x}$ a variável tempo em dias após emergência, foi ajustada a variação temporal do número de folhas.

\section{RESULTADOS}

As médias de temperatura, fotoperíodo e umidade do ar variaram pouco entre as safras 2007/2008 e 2008/2009, enquanto que para a precipitação pluvial ocorreu uma variação acentuada (Figura 1). As precipitações ocorridas na safra 2008/2009 foram acima da necessidade da cultura. Nos meses de novembro e abril, ocorreram precipitações de 350 e $450 \mathrm{~mm}$, respectivamente. No primeiro ano verificouse a ocorrência de veranico entre os meses de dezembro e janeiro, fato frequentemente observado na região (SEIA, 2007; Cruz et al., 2010). Na safra 2008/2009 ocorreram precipitações acima da média da região, sem a ocorrência de veranicos (AIBA, 2011).

A doença predominante nas duas safras foi a FAS, tendo sido registrado apenas traços das doenças de final de ciclo.O modelo logístico foi o que melhor se ajustou aos dados de severidade da doença para as duas safras (Figuras 2 e 3). Tsumanuma et al. (2010) relatam esse modelo como o que melhor se adapta as curvas de progresso dessa doença. Devido à baixa severidade da FAS, não foi possível ajustar o modelo logístico na EP1 para as parcelas com controle em ambas as safras, para todos as cultivares. Para a cultivar
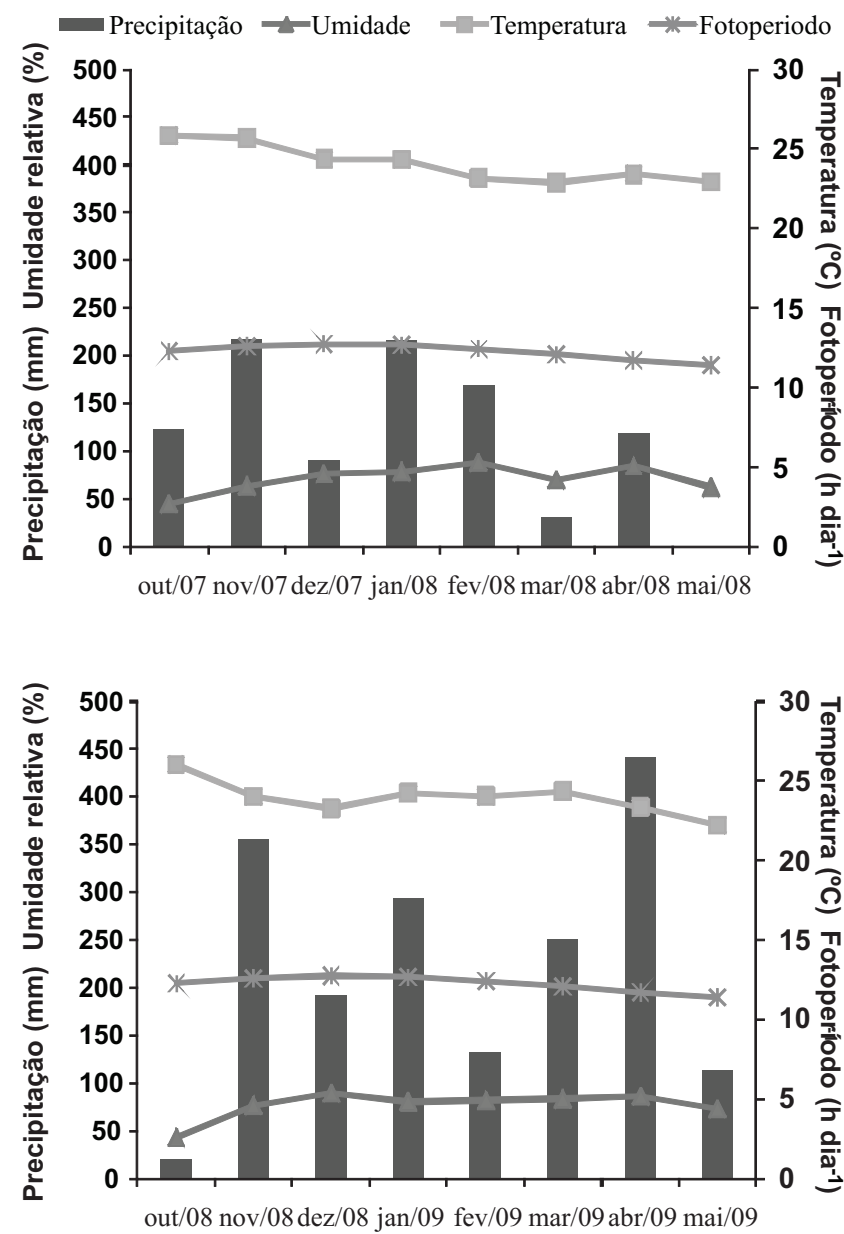

FIGURA 1 - Valores médios mensais de precipitação pluvial total $(\mathrm{mm})$, umidade relativa do ar $(\%)$, fotoperíodo $\left(\mathrm{h} \mathrm{dia}^{-1}\right)$, correspondente ao $15^{\circ}$ dia do mês e temperatura do ar $\left({ }^{\circ} \mathrm{C}\right)$ durante os meses de outubro a maio de 2007/2008 e 2008/2009 na Fazenda Maria Gabriela, município de São Desidério, BA.

Monsoy 8411 na safra 2007/2008 não foi possível o ajuste na EP1 sem controle e na EP2 com controle, em ambas a safras.

Nas parcelas sem controle as cultivares BRS Corisco (ciclo médio) e BRS Barreiras (ciclo tardio), apresentaram severidade média de ferrugem de $22 \%$ e de $42 \%$, na EP1, respectivamente, na safra 2007/2008. Na safra 2008/2009, também na primeira época de semeadura, esses valores foram de $62 \%$ e de $68 \%$, respectivamente. As épocas de semeadura tardia (EP3) proporcionaram maiores valores médios da severidade da ferrugem em ambas as situações (com e sem controle químico). Nas parcelas sem controle constatou-se, em todas as cultivares, valores de severidade próximos a $100 \%$.

Os estádios fenológicos em que a epidemia teve início variaram entre as safras, entre as épocas de semeadura e entre as cultivares (Tabela 1, Figuras 2 e 3 ). $\mathrm{Na}$ safra 2007/2008 verificou-se que nas épocas de semeadura 


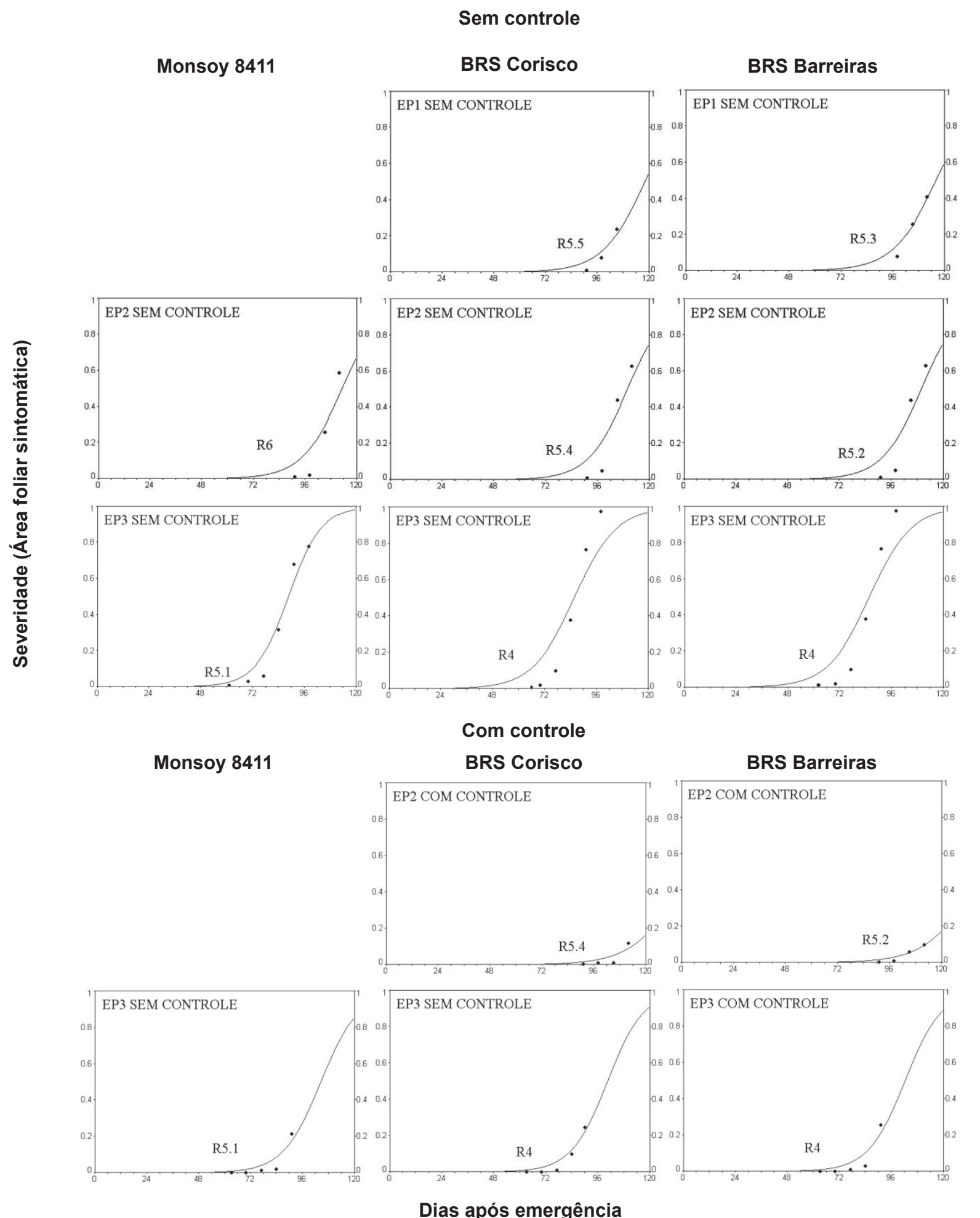

FIGURA 2 - Curvas de progresso da ferrugem asiática da soja (FAS) nos cultivares Monsoy 8411, BRS Corisco e BRS Barreiras em diferentes épocas de semeadura (29/11/2007-EP1, 20/12/2007-EP2 e 12/01/08-EP3) na safra 2007/2008, Fazenda Maria Gabriela, São Desidério, BA. 


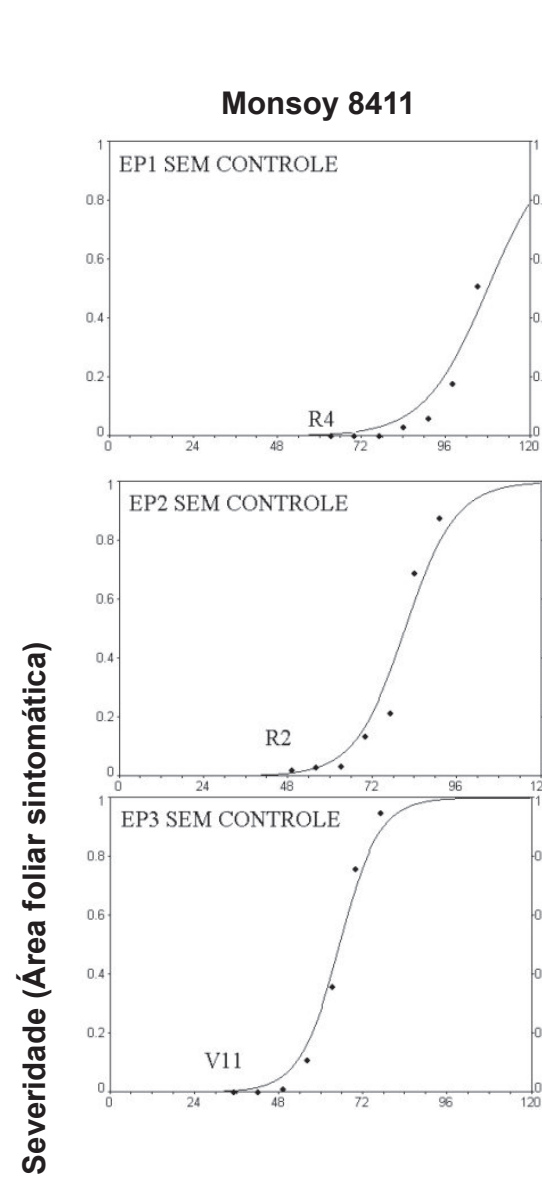

Monsoy 8411

\section{Sem controle}

BRS Corisco
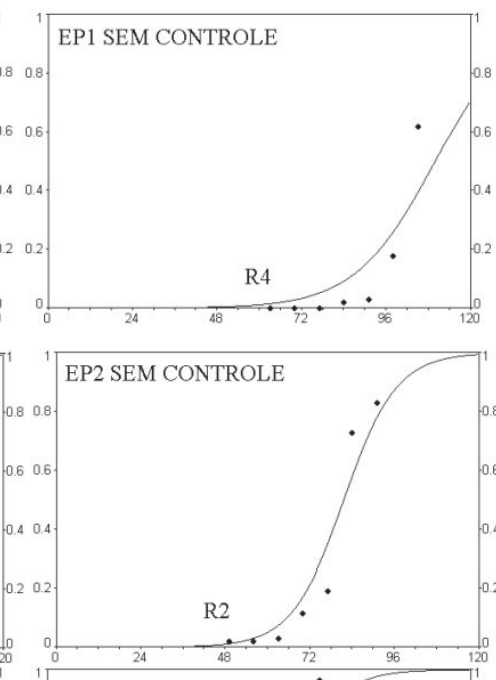

EP3 SEM CONTROLE

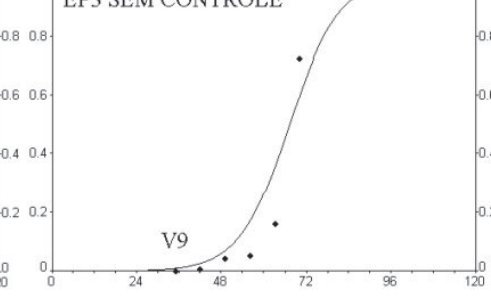

Com controle

BRS Corisco
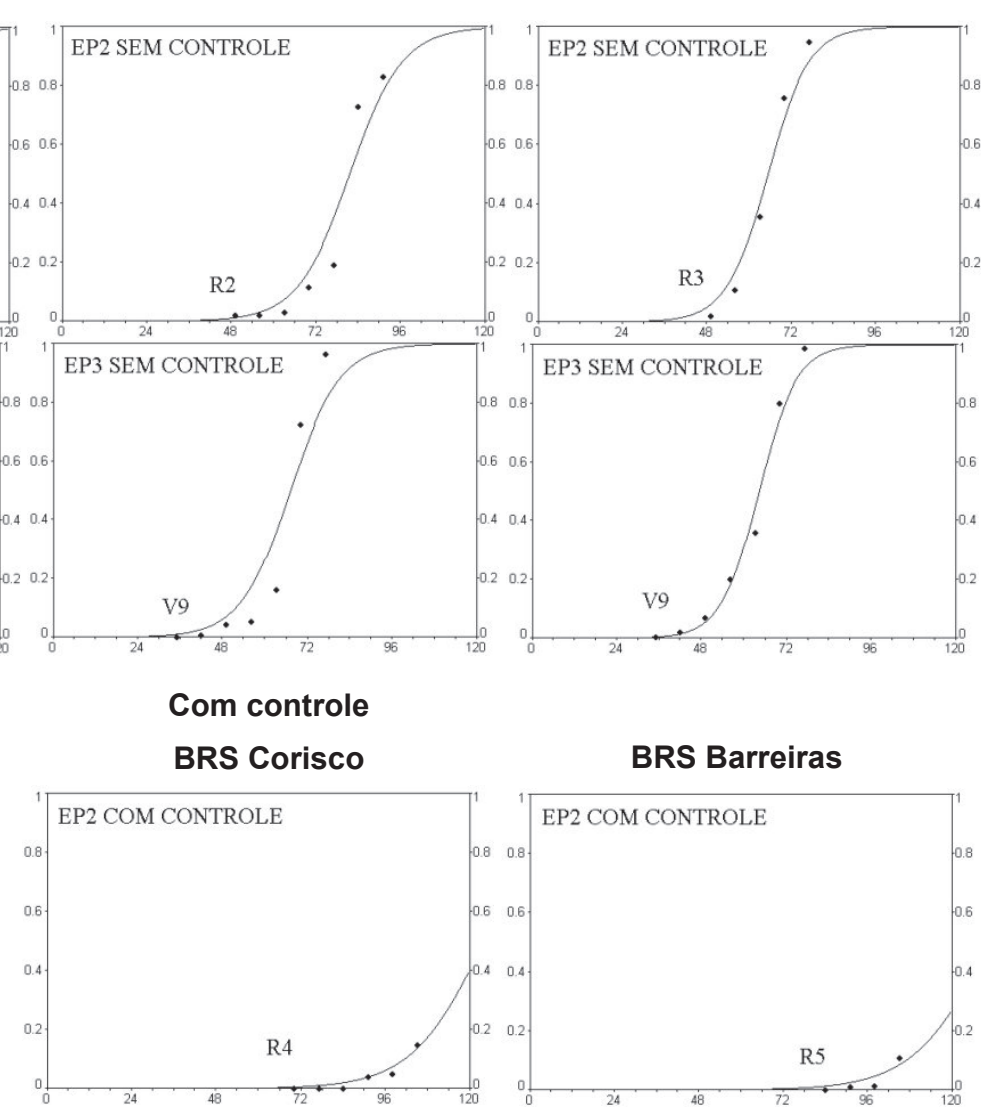

\section{BRS Barreiras}

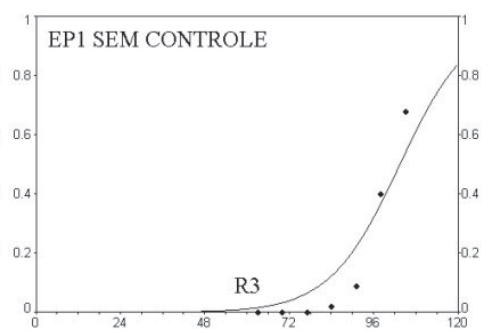

\section{BRS Barreiras}

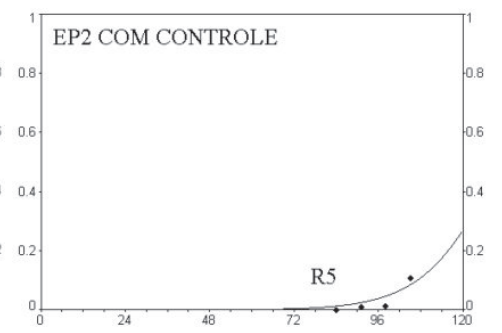

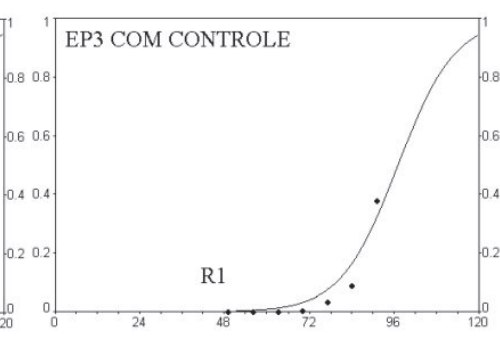

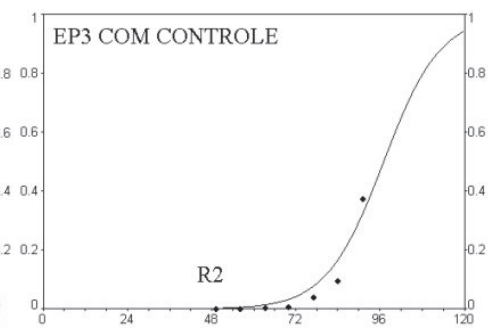

Dias após emergência

FIGURA 3 - Curvas de progresso da ferrugem asiática da soja (FAS) nos cultivares Monsoy 8411, BRS Corisco e BRS Barreiras em diferentes épocas de semeadura (04/12/2008-EP1, 22/12/2008-EP2 e 14/01/2009-EP3) na safra 2008/2009, Fazenda Maria Gabriela, São Desidério, BA. 
TABELA 1 - Valores médios da área abaixo da curva de progresso da doença padronizada (AACPDp) das cultivares de soja Monsoy 8411, BRS Corisco e BRS Barreiras em três épocas de semeadura $(E P 1=29 / 11 / 07,04 / 12 / 08 ;$ EP2 = 20/12/07, 22/12/08 e EP3 = 12/01/08, 14/01/09) com e sem controle químico da ferrugem asiática (C/C e S/C, respectivamente), na região oeste da Bahia, nas safras 2007/2008 e $2008 / 2009$

\begin{tabular}{|c|c|c|c|c|}
\hline \multirow[b]{2}{*}{ CULTIVARES } & \multicolumn{4}{|c|}{ SAFRA 2007/2008 } \\
\hline & CONTROLE & EP1 & EP2 & EP3 \\
\hline \multirow[t]{3}{*}{ MONSOY 8411} & $\mathrm{C} / \mathrm{c}$ & $0,00 \mathrm{aB}$ & $0,94 \mathrm{bB}$ & $10,20 \mathrm{bA}$ \\
\hline & $\mathrm{S} / \mathrm{c}$ & $0,40 \mathrm{aB}$ & $39,06 \mathrm{aA}$ & $39,91 \mathrm{aA}$ \\
\hline & MÉDIA & $0,20 \mathrm{C}$ & $20,00 \mathrm{~B}$ & $2505 \mathrm{~A}$ \\
\hline \multirow[t]{3}{*}{ BRS CORISCO } & $\mathrm{C} / \mathrm{c}$ & $0,69 \mathrm{bB}$ & $2,48 \mathrm{bB}$ & $11,99 \mathrm{bA}$ \\
\hline & $\mathrm{S} / \mathrm{c}$ & $9,65 \mathrm{aB}$ & $49,66 \mathrm{aA}$ & $41,91 \mathrm{aA}$ \\
\hline & MÉDIA & $5,17 \mathrm{~B}$ & $26,07 \mathrm{~A}$ & $26,95 \mathrm{~A}$ \\
\hline \multirow[t]{4}{*}{ BRS BARREIRAS } & $\mathrm{C} / \mathrm{c}$ & $0,96 \mathrm{bB}$ & $6,51 \mathrm{bAB}$ & $12,49 \mathrm{bA}$ \\
\hline & $\mathrm{S} / \mathrm{c}$ & $16,73 \mathrm{aB}$ & $42,68 \mathrm{aA}$ & $51,06 \mathrm{aA}$ \\
\hline & MÉDIA & $8,84 \mathrm{C}$ & $24,59 \mathrm{~B}$ & $31,77 \mathrm{~A}$ \\
\hline & \multicolumn{4}{|c|}{ SAFRA 2008/2009 } \\
\hline CULTIVARES & CONTROLE & EP1 & EP2 & EP3 \\
\hline \multirow{3}{*}{ MONSOY 8411} & $\mathrm{C} / \mathrm{c}$ & $0,34 \mathrm{bB}$ & $0,52 \mathrm{bB}$ & $12,47 \mathrm{bA}$ \\
\hline & $\mathrm{S} / \mathrm{c}$ & $9,03 \mathrm{aC}$ & $40,79 \mathrm{aB}$ & $54,07 \mathrm{aA}$ \\
\hline & MÉDIA & $4,69 \mathrm{C}$ & $20,66 \mathrm{~B}$ & $33,27 \mathrm{~A}$ \\
\hline \multirow[t]{3}{*}{ BRS CORISCO } & $\mathrm{C} / \mathrm{c}$ & $0,25 \mathrm{bB}$ & $1,68 \mathrm{bB}$ & $12,04 \mathrm{bA}$ \\
\hline & $\mathrm{S} / \mathrm{c}$ & $13,65 \mathrm{aC}$ & $41,65 \mathrm{aB}$ & $48,03 \mathrm{aA}$ \\
\hline & MÉDIA & $6,95 \mathrm{C}$ & $21,67 \mathrm{~B}$ & $30,03 \mathrm{~A}$ \\
\hline \multirow[t]{3}{*}{ BRS BARREIRAS } & $\mathrm{C} / \mathrm{c}$ & $0,24 \mathrm{bB}$ & $3,40 \mathrm{bB}$ & $11,69 \mathrm{bA}$ \\
\hline & $\mathrm{S} / \mathrm{c}$ & $36,62 \mathrm{aC}$ & $48,03 \mathrm{aB}$ & $58,45 \mathrm{aA}$ \\
\hline & MÉDIA & $18,43 \mathrm{C}$ & $25,71 \mathrm{~B}$ & $3507 \mathrm{~A}$ \\
\hline
\end{tabular}

Médias seguidas pela mesma letra maiúscula na linha e minúscula na coluna, não diferem entre si pelo teste de Tukey, a 5\% de probabilidade.

do período preferencial (EP1 e EP2) o início da infecção ocorreu em torno dos 90 DAE (Figura 2), correspondendo a diferentes estádios fenológicos, conforme a cultivar (estádio R5.5 para BRS Corisco, R5.3 para BRS Barreiras na EP1, enquanto que na EP2, estádio R6 para Monsoy 8411, R5.4 para BRS Corisco e R5.2 para BRS Barreiras). Observou-se que na EP3 a epidemia teve início aos $65 \mathrm{DAE}$, coincidindo com os estádios fenológicos R4 nos cultivares BRS Corisco e BRS Barreiras e com estádio R5.1 em Monsoy 8411 (Figura 2).

Na safra 2008/2009 (Figura 3), com maior incidência de chuvas, antecipou-se o início da epidemia em todas as épocas de semeadura quando comparado com a safra anterior. Os primeiros sintomas da FAS foram observados na EP1 aos 65 DAE quando a cultivar Monsoy 8411 e a BRS Corisco encontravam-se no estádio fenológico R4 e a cultivar BRS Barreiras em R3. Na EP2 ocorreu em torno dos 50 DAE, quando a cultivar Monsoy 8411 e a BRS Corisco estavam em pleno florescimento (R2) e a BRS Barreiras em R3. Na época de semeadura tardia (EP3) a epidemia teve início aos $35 \mathrm{DAE}$, coincidindo com a fase vegetativa de todos as cultivares.

Nas parcelas com controle químico na EP2 e EP3, verificou-se que apesar da ocorrência da doença, a severidade manteve-se abaixo de $5 \%$ de severidade durante as fases de florescimento (R1) e enchimento de grão (R5)
(Figura 3). No momento em que se observou severidade mais elevada, os cultivares já se encontravam nas fases finais do desenvolvimento, nos estádios R6 (sementes formadas) e R7 (maturidade fisiológica).

Para cada cultivar, em cada época de semeadura, submetido ao controle ou não da FAS, os maiores valores da AACPDp foram obtidos na safra 2008/2009 (Tabela1). No entanto, houve a mesma tendência nas duas safras, ou seja, para cada cultivar, constataram-se maiores valores da AACPDp quando não houve o controle da FAS, sendo isso observado em todas as épocas de semeadura. Maiores valores da AACPDp foram observados à medida que se atrasou a semeadura em ambas as safras, ou seja, quando a doença não foi controlada. Na EP3 e EP2 todos os cultivares apresentaram os maiores valores da AACPDp e na EP1 os menores valores, mostrando haver diferenças entre as épocas de semeadura quando se considera a FAS.

$\mathrm{Na}$ safra 2007/2008 registrou-se na cultivar Monsoy 8411 (ciclo precoce), quando não houve o controle da FAS uma AACPDp de 0,40 na EP1 e de 39,91 na EP3, representando aumento de 100 vezes (relação de $1 / 100$ ) quando a semeadura foi realizada tardiamente. Calculando essas relações para os demais cultivares nessa mesma safra, obtiveram-se proporções de 1/4 para BRS Corisco (ciclo médio) e 1/3 para BRS Barreiras (ciclo 
tardio). Na 2008/2009 as proporções foram de 1/6 no cultivar Monsoy 8411, 1/3,5 para o BRS Corisco e 1/1,5 para o BRS Barreiras.

A variável número de folhas ao longo do ciclo da cultura foi ajusta pela função polinomial exponencial $\mathrm{Ln}$ $(y)=a+b x^{1,5}+c^{0,5}$, com coeficientes de determinação $\left(\mathrm{R}^{2}\right)$ que variaram de 0,72 a 0,99 . As desfolhas promovidas pela FAS começaram a ser observadas a partir dos 75 DAE, ficando mais acentuadas após os $90 \mathrm{DAE}$, em todas as épocas e em ambas as safras (Figura 4). A exceção foi a cultivar Monsoy 8411 na EP1 na safra 2007/2008, que apresentou o número de folhas similar nas parcelas com e sem controle da FAS, durante todo o ciclo.

Comparando-se o número de folhas das plantas com e sem controle aos 90 DAE na safra 2007/2008, verificou-se que na EP1 o cultivar BRS Corisco teve o número de folhas reduzido de 59 para 52 folhas planta $^{-1}$ e a cultivar BRS Barreiras de 32 para 22 folhas planta ${ }^{-1}$. Na EP2, essa redução também foi observada, sendo nas cultivares Monsoy 8411 de 30 para 22 folhas planta $^{-1}$, na BRS Corisco de 40 para 27 e na BRS Barreiras de 31 para 18 enquanto que, na EP3 na cultivar BRS Corisco a redução foi de 23 para 13 e na BRS Barreiras de 15 para 10 folhas planta ${ }^{-1}$, decréscimos da ordem de $44 \%$ e $34 \%$, respectivamente. Nesta última época de semeadura, a cultivar Monsoy 8411, aos 90 DAE, apresentou $100 \%$ de desfolha quando a ferrugem não foi controlada, enquanto que, com o controle, apresentou 11 folhas planta ${ }^{-1}$.

Na safra 2008/2009 com a ocorrência de maiores severidades da FAS, as desfolhas ficaram mais acentuadas para todos as cultivares em todas as épocas (Figura 4). Na EP1 aos 120 DAE, foram verificados valores médios de 18 e 12 folhas planta ${ }^{-1}$ nas cultivares BRS Corisco e na BRS Barreiras, respectivamente, quando foi aplicado fungicida para o controle da doença, em contrapartida, ao não se realizar o controle da doença, verificou-se $100 \%$ de desfolha em ambas as cultivares. Na EP2, com o controle da doença, a última avaliação ocorreu aos 105 DAE com valores médios do número de folhas por planta de 14 na Monsoy 8411, 21 na BRS Corisco e 18 na BRS Barreiras, com total desfolha nas parcelas sem controle. Essa mesma tendência foi observada na época tardia (EP3) em que as cultivares BRS Corisco e BRS Barreiras apresentaram, respectivamente, 7 e 6 folhas planta $^{-1}$, aos 105 DAE nas parcelas que receberam aplicação de fungicida e total desfolha nas parcelas sem o controle da doença (Figura 4).

Constatou-se que os maiores valores médios de produtividade de grãos foram obtidos nas épocas de semeadura do período preferencial, onde se destacou a EP1 (Tabela 2). Registraram-se diferenças significativas $(p<0,05)$ entre as parcelas com e sem controle para as cultivares, em ambas as safras, com exceção do cultivar Monsoy 8411, na safra 2007/2008, quando as diferenças não foram significativas.

Com severidades que tenderam à máxima, os danos da FAS na produtividade foram acentuados na safra
2008/2009 (Figura 3), quando verificaram-se perdas que variaram de $1.777 \mathrm{~kg} \mathrm{ha}^{-1}$ para a cultivar Monsoy 8411 na EP1 a $728 \mathrm{~kg} \mathrm{ha}^{-1}$ para a cultivar BRS Corisco na EP3. Embora tenham sido observadas as maiores diferenças entre as parcelas com e sem controle nas épocas preferenciais (EP1 e EP2), foi na época tardia (EP3) que se registraram as maiores reduções, sendo de $69 \%$ para a cultivar Monsoy $8411,60 \%$ para a BRS Corisco e $80 \%$ para a BRS Barreiras. Estes resultados estão de acordo com os observados por Hartman et al. (1991), Kawuki et al. (2003), Costamilan et al. (2005) e Hikishima et al. (2010).

\section{DISCUSSÃO}

De acordo com Raper \& Kramer (1987) a faixa de uso da água pela cultura da soja varia de 450 a $825 \mathrm{~mm}$ de água, durante o ciclo, dependendo do número de dias necessários para a finalização deste e das condições climáticas. Câmara \& Heiffig (2002) por sua vez, consideram que regiões com precipitações médias, durante o ciclo da cultura, entre 500 e $700 \mathrm{~mm}$, e boa distribuição, como aptas ao desenvolvimento da cultura. Dessa forma, nas duas safras as condições climáticas foram adequadas para a da cultura, mas, também propiciaram o desenvolvimento do fungo causador da ferrugem, sendo na safra 2008/2009, onde se verificou maior severidade da doença (Figuras 2 e 3), devido às elevadas e constantes precipitações.

Com o atraso das épocas de semeadura observouse aumento da severidade da FAS, principalmente nas semeaduras mais tardias (EP3). Essa tendência foi constatada nas duas safras incluídas na pesquisa. Maiores severidades da ferrugem nas épocas de semeadura tardia também foram observadas por Hikishima et al. (2010) ao avaliarem a severidade da FAS em duas épocas de semeadura em dois anos agrícolas, em Londrina, PR. Estes mesmos autores constataram que os diferentes estádios fenológicos em que a epidemia teve início, interferiram na severidade e na produtividade de cultivares de soja nas diferentes épocas de semeadura.

Aocorrência antecipada da FAS e o crescente aumento de sua severidade, com o atraso das semeaduras, indicam que a EP1 foi a época em que ocorreu a menor pressão do inóculo, mesmo quando comparada à EP2, considerada nesse estudo como o final do período preferencial para a região Oeste da Bahia. A explicação para o fenômeno é dada por Oliveira et al. (2005), que ressaltam que o fungo causador da ferrugem, por ser um patógeno biotrófico e policíclico, inicia sua multiplicação nas primeiras semeaduras, estando as plantas semeadas neste período sujeitas a uma menor pressão de inóculo. Tais características evidenciam a importância da adoção do vazio sanitário na região Oeste da Bahia, uma vez que essa prática proporcionaria uma redução do inóculo nas semeaduras realizadas no início do período preferencial.

A baixa severidade observada na cultivar Monsoy 8411, nas parcelas sem controle da primeira época de 

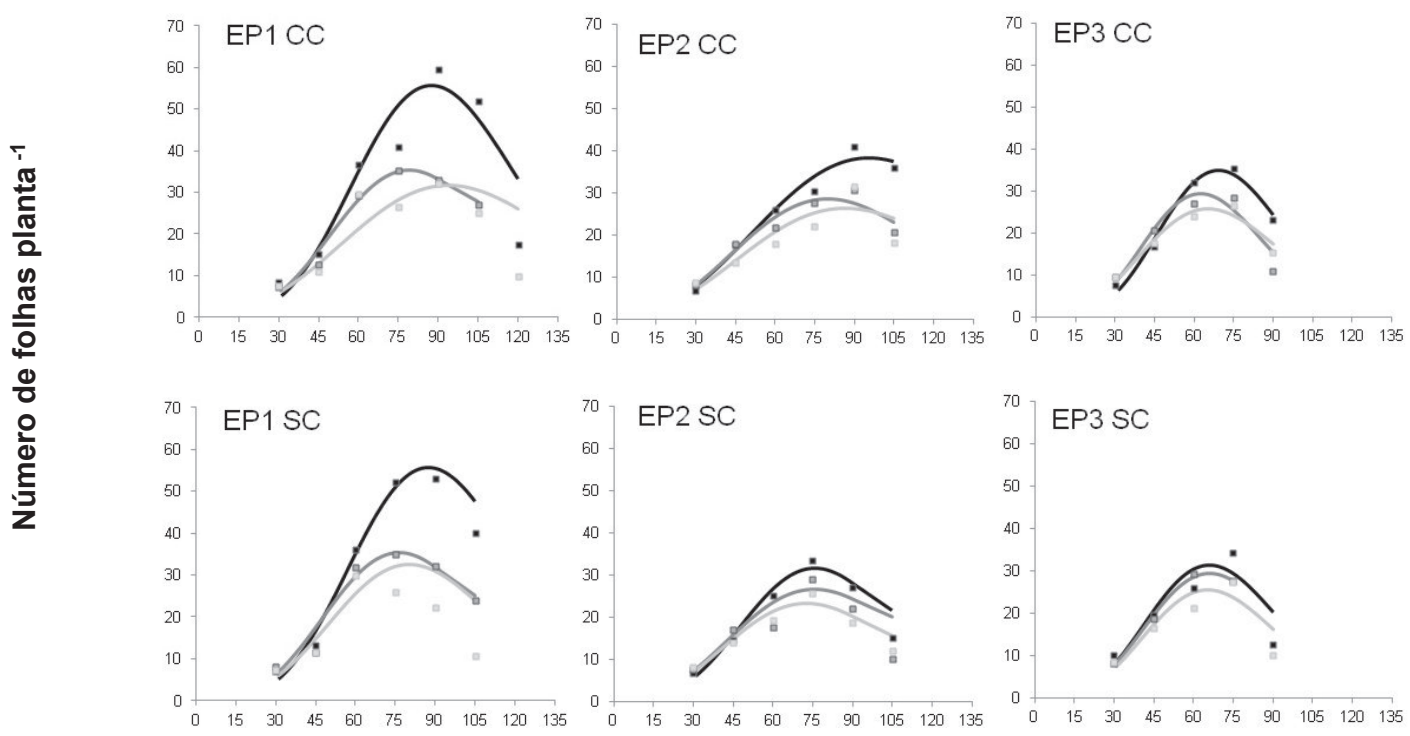

Dias após emergência

\section{SAFRA 2008/2009}
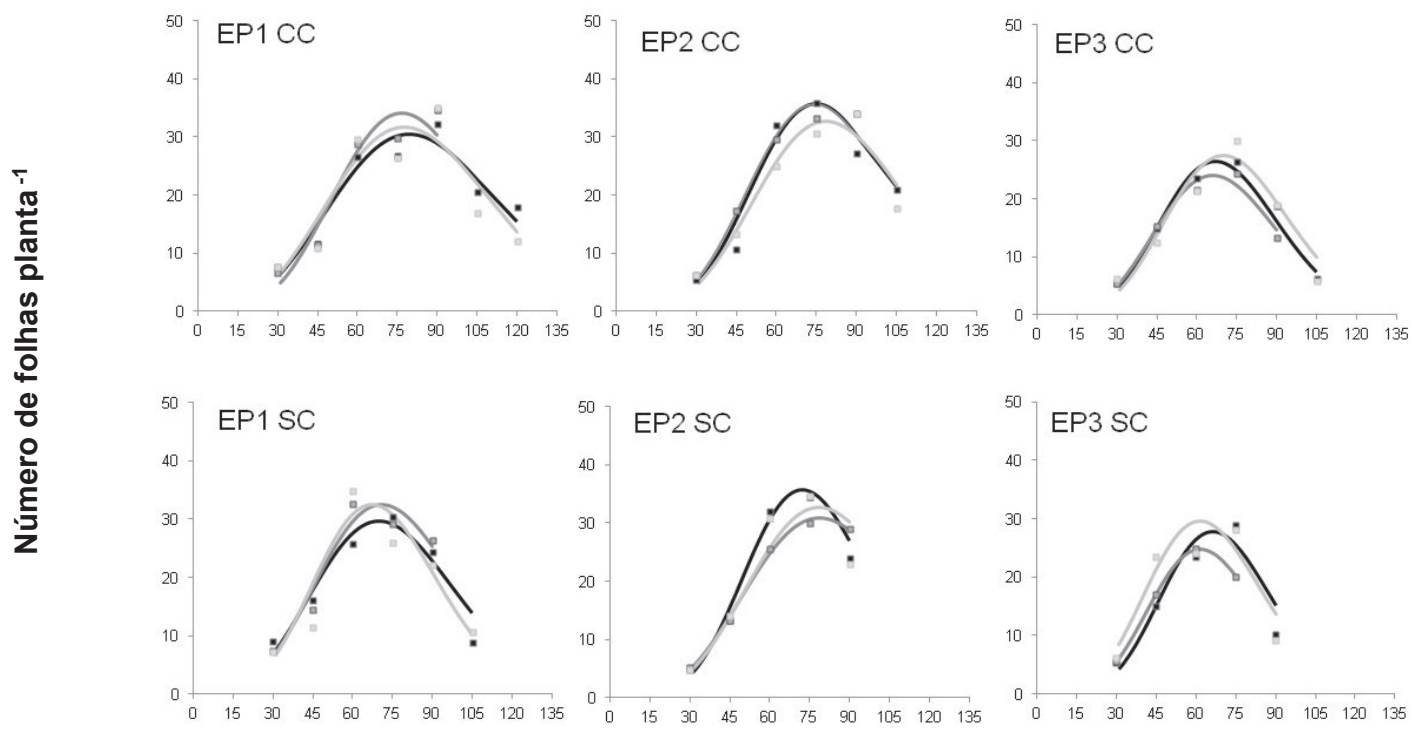

Dias após emergência

\begin{tabular}{lll} 
BRS CORISCO & MSOr 8411 & BRS BARREIRAS \\
\cline { 2 - 2 } & média & média
\end{tabular}

FIGURA 4 - Curvas polinomiais para número de folhas planta-1 em dias após a emergência, dos cultivares de soja Monsoy 8411 , BRS Corisco e BRS Barreiras em três épocas de semeadura (EP1 = 29/11/07, 04/12/08; EP2 = 20/12/07, 22/12/08 e EP3 = 12/01/08, 14/01/09) com e sem controle químico da ferrugem asiática (CC e SC, respectivamente), na região oeste da Bahia, nas safras 2007/2008 e 2008/2009, ajustadas a função $\operatorname{Ln}(y)=a+b x^{1,5}+c^{0,5}$. 
TABELA 2 - Valores médios de produtividade de grãos $\left(\mathrm{kg} \mathrm{ha}^{-1}\right)$ dos cultivares de soja Monsoy 8411, BRS Corisco e BRS Barreiras em três épocas de semeadura $(\mathrm{EP} 1=29 / 11 / 07,04 / 12 / 08 ; \mathrm{EP} 2=20 / 12 / 07,22 / 12 / 08$ e EP3 = 12/01/08, 14/01/09) com e sem controle químico da ferrugem asiática (CC e SC, respectivamente) e suas respectivas diferenças, na região oeste da Bahia, nas safras 2007/2008 e $2008 / 2009$

\begin{tabular}{|c|c|c|c|c|}
\hline \multirow[b]{2}{*}{ Épocas } & \multicolumn{4}{|c|}{$\begin{array}{c}\text { Safra } 2007 / 2008 \\
\text { Produtividade }\left(\mathrm{kg} \mathrm{ha}^{-1}\right)\end{array}$} \\
\hline & Cultivares & $\mathrm{CC}$ & SC & Diferença \\
\hline \multirow[t]{3}{*}{ Ep1 } & Monsoy 8411 & 3036 & 2822 & $214^{\mathrm{ns}}$ \\
\hline & Brs Corisco & 3496 & 2898 & $598^{* *}$ \\
\hline & Brs Barreiras & 3907 & 2909 & $998^{* *}$ \\
\hline \multirow[t]{3}{*}{ Ep2 } & Monsoy 8411 & 2729 & 2512 & $217^{\mathrm{ns}}$ \\
\hline & BRS Corisco & 3002 & 2633 & $369^{*}$ \\
\hline & BRS Barreiras & 2949 & 2368 & $581^{* *}$ \\
\hline \multirow[t]{4}{*}{ Ep3 } & Monsoy 8411 & 2283 & 2038 & $245^{\mathrm{ns}}$ \\
\hline & BRS Corisco & 2520 & 1897 & $623^{* *}$ \\
\hline & BRS Barreiras & 1958 & 1389 & $569^{* *}$ \\
\hline & \multicolumn{4}{|c|}{$\begin{array}{c}\text { Safra 2008/2009 } \\
\text { Produtividade }\left(\mathrm{kg} \mathrm{ha}^{-1}\right)\end{array}$} \\
\hline Épocas & Cultivares & $\mathrm{CC}$ & SC & Diferença \\
\hline \multirow[t]{3}{*}{ EP1 } & Monsoy 8411 & 3079 & 1302 & $1777^{* *}$ \\
\hline & BRS Corisco & 2663 & 1290 & $1373^{* *}$ \\
\hline & BRS Barreiras & 2772 & 1469 & $1393^{* *}$ \\
\hline \multirow[t]{3}{*}{ EP2 } & Monsoy 8411 & 2475 & 832 & $1643^{* *}$ \\
\hline & BRS Corisco & 2179 & 831 & $1348^{* *}$ \\
\hline & BRS Barreiras & 2328 & 1189 & $1139^{* *}$ \\
\hline \multirow[t]{3}{*}{ EP3 } & Monsoy 8411 & 1373 & 435 & $938^{* *}$ \\
\hline & BRS Corisco & 1223 & 495 & $728^{* *}$ \\
\hline & BRS Barreiras & 1596 & 364 & $1232^{* *}$ \\
\hline
\end{tabular}

*Significativo a $5 \%$;* Significativo a $1 \%$ pelo teste de Tukey; ns = não significativo

semeadura, na safra 2007/2008 (Figura2), que impossibilitou o ajuste ao modelo logístico, não pode ser atribuída a uma possível resistência do cultivar, pois no momento em que a severidade foi mais elevada, as plantas já se encontravam na fase final de desenvolvimento. Além disso, na safra 2008/2009, esse cultivar apresentou severidades acima de 50\%, ainda na EP1 (Figura 3). Esse resultado pode ser atribuído a um escape do cultivar em relação ao patógeno, devido à presença de menor quantidade de inóculo na época inicial de semeadura por ocasião da primeira semeadura em 2007/2008.

Assim como na severidade, pode-se observar nos valores médios da AACPDp que a safra 2008/2009 foi mais favorável à ocorrência da FAS que a safra 2007/2008. Na safra 2008/2009 registrou-se o maior valor da AACPDp de todo experimento quando a doença não foi controlada com fungicida (EP3, BRS Barreiras). Esses resultados são explicados pelas condições climáticas favoráveis e a maior pressão de inóculo verificada em semeaduras tardias.

A partir dos resultados da AACPDp em ambas as safras, ficou evidente que as épocas consideradas tardias (EP3) são mais favoráveis a FAS no Oeste da Bahia, estando de acordo com Costamilan et al. (2005), Carneiro (2007) e Hikishima et al. (2010). O impacto proporcionado pelo patógeno é potencializado nas semeaduras realizadas em janeiro (EP3), o que promove uma AACPDp expressivamente maior que a primeira época de semeadura (Figuras 2 e 3).

A diferença de valores proporcionais da AACPDp entre a EP1 para a EP3 verificada na cultivar Monsoy 8411 deve ser atribuída à baixa severidade da doença registrada na primeira época de semeadura (EP1). A cultivar BRS Barreiras foi a que apresentou os maiores valores médios da AACPDp e as menores diferenças entre as épocas de semeadura, em ambas as safras, devido ao seu ciclo de maturação tardio. Essas observações estão em conformidade com Michel et al. (2000), que avaliando a reação de genótipos de soja as doenças de final de ciclo, verificaram que nas cultivares de ciclo precoce o fungo tem menos tempo para causar redução de produtividade, em função das mesmas ficarem menor tempo no campo, enquanto que os cultivares de ciclo tardio apresentam maior intensidade de doenças de final de ciclo, por permanecerem mais tempo expostas aos patógenos no campo. Para a região Oeste da Bahia, a utilização de cultivares precoces, semeadas no início da época recomendada, representada pela EP1, é uma prática de manejo que poderá promover redução de riscos em relação à FAS e aliada a adoção do vazio sanitário na 
região, tornam-se fundamentais para o manejo da FAS e a sustentabilidade da sojicultura baiana.

A quantificação do número de folhas por planta permitiu diferenciar a senescência natural daquela provocada pela FAS. A queda de folhas causada pela senescência natural pôde ser observada nas parcelas com controle da doença, onde foi constatado que com o atraso da época de semeadura, da EP1 para EP3, as cultivares apresentaram menor número de folhas em cada planta além de encurtamento no seu ciclo (Figura 4). Em cada época de semeadura, ao se comparar as cultivares que receberam fungicida para o controle da ferrugem com as que não receberam observa-se um menor número de folhas por planta quando não houve o controle e principalmente a queda antecipada das folhas. A constatação da presença da ferrugem ocasionando a desfolha precoce também foi observada por Yang et al. (1991).

A produtividade de grãos das diferentes cultivares e épocas de semeadura, de maneira geral, foi menor na safra 2008/2009, o que pode ser explicado pelas condições climáticas favoráveis ao desenvolvimento do fungo e, consequentemente, maior severidade da FAS (Tabela 1 e 2, Figuras 1, 2, 3). Entre as épocas de semeadura foram observadas as menores produtividades na EP3, pois, os cultivares nesta época ficaram submetidos a maior pressão de inóculo da doença, como demonstrado pelo aparecimento mais precoce da ferrugem (no estádio vegetativo ou início do florescimento), maior severidade, maior valor da AACPDp e desfolha antecipada. As cultivares BRS Corisco, de ciclo médio, e a BRS Barreiras de ciclo tardio, tiveram sua produtividade reduzida em função da FAS nas duas safras, diferentemente da Monsoy 8411, provavelmente devido ao seu ciclo de maturação precoce, consequentemente ficando menos tempo no campo e, portanto, com menor exposição ao inóculo.

A cultivar Monsoy 8411, de maturação precoce, constitui-se em opção viável para o manejo da FAS, inclusive no que se refere à redução de custos de produção. Provavelmente demandará menor número de aplicações de fungicidas em condições de menor pressão do inóculo, como ocorreu na safra 2007/2008, além de ter apresentado estabilidade de produção com a variação das épocas de semeadura, não sendo observadas diferenças estatísticas entre as épocas na primeira safra. Resultados semelhantes foram obtidos por Lopes et al. (2009) ao trabalhar com sete cultivares de soja, entre estes, a Monsoy 8411 na região Oeste da Bahia, em três situações: sem controle da ferrugem, uma e duas aplicações de fungicidas para o controle da doença, tendo sido verificado que essa cultivar escapou da doença, devido ao seu ciclo precoce de maturação. Isso demonstra que a escolha adequada dos cultivares de soja para a semeadura poderá maximizar a renda do produtor rural.

A utilização de cultivares de ciclo precoce semeadas no início do período considerado preferencial (final de novembro e início de dezembro), na região oeste da
Bahia, é uma prática de manejo viável no controle da FAS. Com o atraso da época de semeadura constatam-se as maiores severidades da ferrugem e consequentemente, maiores reduções na produtividade de grãos dos cultivares, independente do ciclo de maturação.

\section{AGRADECIMENTOS}

A Coordenação de Aperfeiçoamento de Pessoal de Nível Superior - CAPES pela bolsa concedida, à Fundação Bahia por disponibilizar o campo experimental e pelo apoio técnico na condução dessa pesquisa e a $\mathrm{ADAB}$ pelo apoio nas avaliações da severidade.

\section{REFERÊNCIAS BIBLIOGRÁFICAS}

AIBA (Associação de Agricultores e Irrigantes da Bahia). Disponível em: www.aiba.org.br/index.php?id=soja. Acesso em: 25 de março de 2011.

Bergamin Filho A(1995) Curvas de progresso da doença. In: Kimati H, Amorim L, Bergamin Filho A, Camargo LEA, Rezende JAM (Eds.) Manual de Fitopatologia. Vol. 1. Princípios e Conceitos. $3^{\mathrm{a}}$ ed. São Paulo SP. Agronômica Ceres. p.602-626.

Câmara GMS, Heiffig LS (2002) Fisiologia, ambiente e rendimento da cultura da soja. In: Câmara GMS (Ed.) Soja - Tecnologia da produção II. Piracicaba SP. ESALQ. p 81-119

Campbell CL, Madden, LV (1990) Introduction to Plant Disease Epidemiology. New York EUA. John Willey \& Sons.

Carneiro LC (2007) Caracterização epidemiológica da resistência parcial e análise da tolerância de genótipos de soja à ferrugem asiática. Tese de Doutorado, USP-Esalq. Piracicaba SP.

CONAB (2003) Previsão e acompanhamento da safra 2002/2003. Quarto levantamento. Disponível em: www.conab.gov.br. Acesso em: 15 de Junho de 2010.

Consórcio Antiferrugem (2009) Custos da ferrugem-asiática. Disponível em: www.consorcioantiferrugem.net/portal/wpcontent/uploads/2010/04/tabela_custos_ferrugem-2009.pdf. Acesso em: 25 de março de 2011.

Costamilan LM, Godoy CV, Roese AD, Santos AM, Andreatta RB (2005) Evolução de ferrugem em quatro épocas de semeadura de soja. Fitopatologia Brasileira 30(Supl.):118.

Cruz TV, Peixoto CP, Martins MC (2010) Crescimento e produtividade de soja em diferentes épocas de semeadura no Oeste da Bahia. Scientia Agraria 11:33-42.

EMBRAPA (2007) Tecnologias de produção de soja: Região Central do Brasil. Londrina PR. Embrapa Soja.

Fehr WR, Caviness CE (1981) Stage of soybean development. Iowa Cooperative Extensive Service, Special Report no. 80. Ames EUA. Iowa State University.

Furlan SH (2004) Impacto, diagnose e manejo da ferrugem asiática da soja no Brasil. Anais, Reunião Itinerante de Fitossanidade do instituto Biológico. Aguaí SP. (CD-ROM).

Godoy CV, Koga LJ, Canteri MG (2006) Diagramatic scale for assessment of soybean rust severity. Fitopatologia Brasileira 31:63-68. 
Hartman GL, Wang TC, Tshanz AT (1991) Soybean rust development and the quantitative relationship between rust severity and soybean yield. Plant Disease 75:596-600.

Hennings P (1903) Some new Japanese uredinales. IV. Hedwigia 42:107-108.

Hikishima M, Canteri MG, Godoy CV, Koga LJ, Silva AJ (2010) Quantificação de danos e relações entre severidade, medidas de refletância e produtividade no patossistema ferrugem asiática da soja. Tropical Plant Pathology 35:96-103.

Kawuki RS, Adipala E, Tukamuhabwa PN (2003) Yield loss associated with soya bean rust (Phakopsora pachyrhizi Syd.) in Uganda. Journal of Phythopatology 151:7-12.

Lopes PVL, Martins MC, Tamai MA, Rocha VA, Tavares JA (2009) Respostas de cultivares de soja ao número de aplicações de fungicidas para o controle da ferrugem. Resumos, V Congresso Brasileiro de Soja e Mercosoja 2009. Londrina PR. Embrapa Soja. p.183.

Madden LV, Hughes G, van den Bosch F (2007). The study of plant disease epidemics. St Paul EUA. APS Press.

Martins MC (2009) Relato da situação da ferrugem e do vazio sanitário no Norte e Nordeste. Reunião do consórcio antiferrugem. Consórcio Antiferrugem. Disponível em: $<$ http://www.consorcioantiferrugem.net/portal//wp-content/ uploads/2010/04/2009_relato_norte_nordeste.pdf> Acesso em: 25 de março de 2011.

Melching JS, Dowler WM, Koogle DL, Royer MH (1989) Effect of duration, frequency, and temperature of leaf wetness period on soybean rust. Plant Disease 73:117-122.

Michel CA, Toledo H, Pereira MJZ, Pereira NMZ (2000) Reação de genótipos de soja a doenças foliares de final de ciclo. Anais, XXVIII Reunião de Pesquisa de Soja da Região Sul. Santa Maria RS. pp.116.

Ogle HJ, Byth DE, Mclean RJ (1979) Effect of rust (Phakopsora pachyrhizi) on soybean yield and quality in south-eastern Queensland. Australian Journal of Agricultural Research 30:833893.

Oliveira ACB, Godoy CV, Martins MC (2005) Avaliação de tolerância de cultivares de soja à ferrugem asiática no Oeste da Bahia. Fitopatologia Brasileira 5:658-662.

Ono Y, Buritica P, Hennen JF (1992) Delimitation of Phakopsora,
Physopella and Cerotelium and their species on Leguminosae. Mycological Research 96:825-850.

Peixoto CP, Câmara GMS, Martins MC, Marchiori LFS, Leonardo V, Mattiazzi P (2000) Épocas de semeadura e densidade de plantas de soja: I. Componentes da produção e rendimento de grãos. Scientia Agricola 57:89-95.

Raper CD, Kramer, PJ (1987) Stress physiology In: Wilcox JR (Ed) Soybean: Improvement, production and uses. $2^{\text {a }}$ ed. Madison EUA. ASA-CSSA-SSSA. p.589-642.

Rytter JL, Dowler WM, Bromfield KR (1984) Additional alternative hosts of Phakopsora pachyrhizi, causal agent of soybean rust. Plant Disease 68:818-819.

SEIA (2007) Sistema estadual de informações ambientais da Bahia: Clima do cerrado. Disponível em: http://www.seia.ba.gov. $\mathrm{br} /$ biorregional/cerrado/template01.cfm?idCodigo $=223$ Acesso em: 25 de junho de 2007.

Sinclair JB, Hartman GL (1999) Soybean rust. In: Hartman GL, Sinclair JB, Rupe JC (Eds.) Compendium of soybean diseases. $4^{\text {a }}$ ed. St. Paul EUA. APS Press. p.3-4.

Sinclair JB, Hartman NGL (1995). Management of Soybean Rust. In: Soybean Rust Workshop, Urbana, I1. Urbana-Champaign, I1. pp. 9-11.

Tsumanuma G, Soares, AR, Fanceli AL, Rodrigues MAT, Bagliomini E (2010) Efeito de herbicidas e fungicidas nas curvas de progresso e quantificação de danos causados pela ferrugem asiática da soja. Ciência Rural 7:1485-1491.

Yang XB, Royer MH, Tschantz AT, Tsia BY (1990) Analysis and quantification of soybean rust epidemics from seventy-three sequential planting experiments. Phytopathology 80:1421-1427.

Yang, XB (1991). Development of yield loss models in relation to reductions of components of soybeans infected with Phakopsora pachyrhizi. Phytopathology 81:1420-1426.

Yorinori JT, Paiva WM, Frederick RD, Costamilan LM, Bertagnolli PF, Hartman GL, Godoy CV, Nunes Junior J (2005) Epidemics of soybean rust (Phakopsora pachyrhizi) in Brazil and Paraguay from 2001 to 2003. Plant Disease 89:675-677.

Yorinori JT, Nunes Junior J, Lazzarotto JJ (2004) Ferrugem "Asiática" da soja no Brasil: evolução, importância econômica e controle. Londrina PR. Embrapa Soja. Documentos 247. 